\title{
Comparative cytotoxicity evaluation of eight root canal sealers
}

\author{
Claudio Poggio ${ }^{\text {, }}$ Paolo Riva ${ }^{1}$, Marco Chiesa ${ }^{1}$, Marco Colombo ${ }^{\text {, }}$, Giampiero Pietrocola ${ }^{2}$ \\ ${ }^{1}$ Department of Clinical-Surgical, Diagnostic and Pediatric Sciences - Section of Dentistry, University of Pavia, Pavia, Italy \\ ${ }^{2}$ Departement of Molecular Medicine, Unit of Biochemistry, University of Pavia, Pavia, Italy
}

Correspondence:

Department of Clinical-Surgical

Diagnostic and Pediatric Sciences - Section of Dentistry, Policlinico "San Matteo"

Piazzale Golgi 3, 27100 Pavia, Italy

claudio.poggio@unipv.it

Poggio C, Riva P, Chiesa M, Colombo M, Pietrocola G. Comparative cytotoxicity evaluation of eight root canal sealers. J Clin Exp Dent. 2017;9(4):e574-8.

http://www.medicinaoral.com/odo/volumenes/v9i4/jcedv9i4p574.pdf

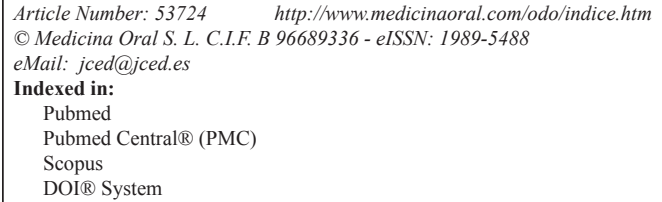

\begin{abstract}
Background: The aim of the present study is to evaluate and compare the cytotoxic effects of eight root canal sealers (BioRoot RCS, TotalFill BC Sealer, MTA Fillapex, Sealapex, AH Plus, EasySeal, Pulp Canal Sealer, N2) on immortalized human gingival fibroblasts over a period of 24, 48 and 72 hours.

Material and Methods: Immortalized human gingival fibroblast-1 HGF-1 (ATCC CRL-2014) were incubated. Root canal sealers were then placed into sterile, cylindrical Teflon moulds. The extraction was made eluting the sealers in cell culture medium. Cells $(1 \times 104)$ were seeded in each well of a 96-well plate and incubated for $24 \mathrm{~h}$ at $37^{\circ} \mathrm{C}$. Cultures were then exposed to $100 \mu \mathrm{L}$ of the extracts medium. The percentage of viable cells in each well was calculated relative to control cells set to $100 \%$.

Results: BioRoot RCS and TotalFill BC Sealer extracted for 24h showed no cytotoxic effect, while it was mild by using 48 and $72 \mathrm{~h}$ extracts. No cytotoxic effect was measured by using AH Plus medium eluted for $24 \mathrm{~h}$, while it was moderate after $48 \mathrm{~h}$ and severe after $72 \mathrm{~h}$. Pulp Canal Sealer, Sealapex and N2 showed moderately cytotoxic activity for all the extraction times. EasySeal and MTA Fillapex remained severely or borderline mildly cytotoxic for all the extraction times.

Conclusions: In the present study only BioRoot RCS, TotalFill BC Sealer and AH Plus showed no cytotoxic effects at least in the first $24 \mathrm{~h}$. All the other sealers revealed moderately or severely cytotoxic activity during all the extraction times.
\end{abstract}

Key words: Cytotoxicity, gingival fibroblast, MTT test, root canal sealer. 


\section{Introduction}

The obturation of root canal systems is one of the most important steps of endodontic treatment. The procedure consists in the three-dimensional filling of the endodontic space in order to prevent the apical and coronal infiltration and the proliferation of microorganisms. Root canals are traditionally filled with gutta-percha points and a root canal sealer. It is widely recognized that sealers if extruded through the apical constriction, may come in direct contact with periapical tissues and may affect them $(1,2)$. Thus, root canal sealers should be non-cytotoxic and biocompatible with periapical tissues (3).

The aim of the present study is to evaluate and compare the cytotoxicity effects of eight root canal sealers on immortalized human gingival fibroblasts over a period of 24,48 and 72 hours.

\section{Material and Methods}

Eigth root canal sealers were selected for this study: BioRoot RCS/silicate-based sealer (Septodont, Saint-Maurdes-Fosses, France), TotalFill BC Sealer/bioceramicbased sealer (FKG Dentaire SA, La Chaux-de-Fonds, Switzerland), EasySeal/resin-based sealer (Komet, Lemgo, Germany), MTA Fillapex/MTA-based sealer (Angelus Dental, Londrina, PR, Brazil), Pulp Canal Sealer/ zinc oxide-eugenol sealer (Kerr, Orange, CA, U.S.A), Sealapex/polymeric calcium hydroxide sealer (Kerr, Orange, CA, U.S.A), N2/zinc oxide-eugenol sealer (Ghimas, Casalecchio di Reno, BO, Italy), AH Plus/resin-based sealer (Dentsply-DeTrey, Konstanz, Germany).

-Cell culture

Immortalized human gingival fibroblast-1 HGF-1 (ATCC CRL-2014) were obtained from the American Type Culture Collection and cultured in high glucose Dulbecco's modified Eagle's medium (DMEM; SigmaAldrich, St. Louis, MO, USA) supplemented with $4 \mathrm{mM}$ L-glutamine (Sigma-Aldrich), 1\% penicillin, streptomycin (Sigma-Aldrich) and 10\% (vol/vol) heat-inactivated fetal bovine serum (FBS; Sigma-Aldrich). Cells were incubated at $37^{\circ} \mathrm{C}$ in $5 \% \mathrm{CO} 2$ atmosphere, fed every $48 \mathrm{~h}$ and routinely sub-cultured every 5 -days with a split ratio of $1: 3$ using trypsin-EDTA (0.05\%; Sigma-Aldrich) for $3 \mathrm{~min}$ at $37^{\circ} \mathrm{C}$.

-Sample preparation

Root canal sealers were prepared according to the manufacturer's recommendation. The sealers were then placed into sterile, cylindrical Teflon moulds which had $4 \mathrm{~mm}$ diameter and $2 \mathrm{~mm}$ height. Excess material was removed with a sterile scalpel and the sealers were carefully removed from Teflon blocks after setting. To prevent contamination, specimens were exposed to UV light for 24 hours after manipulation. Each sealer was immersed in extraction medium immediately after setting.

-Preparation of the extract

The extraction was made eluting the sealers in cell cul- ture medium (see cell culture paragraph) using the surface area-to-volume ratio of approximately $1.25 \mathrm{~cm}^{2} / \mathrm{ml}$ between the surface of the samples and the volume of medium (4). The extraction vials were the incubated at $37^{\circ} \mathrm{C}$ for 24 hours, 48 hours or 72 hours. The specimens were then discarded and the elute extracts were filtered by $0.22-\mu \mathrm{m}$ pore size membranes (Millipore; Billerica, MA, USA). Control samples containing only culture medium were similarly treated. Undiluted extracts were used for the testing.

-Cytotoxicity Test

Cells $(1 \times 104)$ were seeded in each well of a 96-well plate and incubated for $24 \mathrm{~h}$ at $37^{\circ} \mathrm{C}$. Cultures were then exposed to $100 \mu \mathrm{L}$ of the extracts medium. Cell cultures with supplemented DMEM (FBS and antibiotics solution) were used as controls. After $24 \mathrm{~h}$, cell viability was determined using the MTT assay. The MTT solution (3-\{4,5-dimethylthiazol-2-yl\}-2,5-diphenyl tetrazolium bromide) (Sigma-Aldrich) in RPMI-1640 without phenol red (Sigma-Aldrich) $(5 \mathrm{mg} / \mathrm{mL})$ was added to each well of culture plate to make final concentration of 0.5 $\mathrm{mg} / \mathrm{mL}$ and the cells were incubated for $4 \mathrm{~h}$ at $37^{\circ} \mathrm{C}$. Then, the supernatant was removed and the resulting formazan was dissolved by adding $100 \mu \mathrm{L}$ DMSO (SigmaAldrich) to each well. The optical density of formazan dye was read at $545 \mathrm{~nm}$ against $620 \mathrm{~nm}$ as background by Elisa reader (Bio-Rad, Hercules, California, USA). The percentage of viable cells in each well was calculated relative to control cells set to $100 \%$. Cytotoxicity responses were rated as severe $(30 \%)$, moderate $(30$ $60 \%)$, mild (60-90\%) or noncytotoxic (>90\%) (5).

\section{Results}

To evaluate cell viability in the presence of the extract from eight root canal sealers, a MTT assay was performed. The results obtained following cell treatment with the extracts are shown in table 1 and collectively represented in figure. 1.

BioRoot RCS and TotalFill BC Sealer extracted for $24 \mathrm{~h}$ showed no cytotoxic effect, while it was mild by using 48 and $72 \mathrm{~h}$ extracts. However, differences in cytotoxicity for all the times were not statistically significant $(p>0.05)$ compared to the control (culture medium only).

No cytotoxic effect was measured by using AH Plus medium eluted for $24 \mathrm{~h}$, while it was moderate after $48 \mathrm{~h}$ and severe after $72 \mathrm{~h}$. The differences in cell viability in the last two extraction times were statistically significant compare to the control $(p<0.05)$. Moreover, differences in viability of the cells treated with $48 \mathrm{~h}$ or $72 \mathrm{~h}$ extraction medium were also statistically significant $(p<0.05)$. Pulp Canal Sealer, Sealapex and N2 showed moderately cytotoxic activity for all the extraction times. Their differences in cytotoxicity were also statistically significant compare to the control $(p<0.05)$. 
Table 1: Cell viability in the presence of the elute extracts from eight root canal sealers.

\begin{tabular}{|c|c|c|c|}
\hline Materials & $24 \mathrm{~h}$ & $48 \mathrm{~h}$ & $72 \mathrm{~h}$ \\
\hline Control, unconditioned medium & $100^{\mathrm{A}, 1}$ & $100^{\mathrm{A}, 1}$ & $100^{\mathrm{A}, 1}$ \\
\hline BioRoot RCS & $93,41^{\mathrm{A}, 1} \pm 5,67$ & $72,15^{\mathrm{A}, 1} \pm 7,53$ & $60,69^{\mathrm{A}, 1} \pm 5,98$ \\
\hline TotalFill BC Sealer & $90,70^{\mathrm{A}, 1} \pm 12,14$ & $62,69871^{\mathrm{A}, 1} \pm 9,70$ & $64,33^{\mathrm{A}, 1} \pm 2,66$ \\
\hline EasySeal & $34,19^{\mathrm{C}, 6} \pm 5,96$ & $31,97^{\mathrm{C}, 6} \pm 7,23$ & $24,19^{\mathrm{C}, 6} \pm 4,18$ \\
\hline MTA Fillapex & $22,30^{\mathrm{C}, 6} \pm 5,92$ & $29,50^{\mathrm{C}, 6} \pm 12,58$ & $19,85^{\mathrm{C}, 6} \pm 3,72$ \\
\hline Pulp Canal Sealer & $40,21^{\mathrm{B}, 2} \pm 17,12$ & $44,79^{\mathrm{B}, 2} \pm 5,94$ & $38,73^{\mathrm{B}, 2} \pm 7,97$ \\
\hline Sealapex & $48,06^{\mathrm{B}, 3} \pm 23,81$ & $47,57^{\mathrm{B}, 3} \pm 0,15$ & $38,38^{\mathrm{B}, 3} \pm 6,59$ \\
\hline $\mathrm{N} 2$ & $49,794^{\mathrm{B}, 4} \pm 29,79$ & $52,14^{\mathrm{B}, 4} \pm 10,51$ & $34,25^{\mathrm{B}, 4} \pm 8,69$ \\
\hline AH Plus & $92,95^{\mathrm{A}, 1} \pm 3,23$ & $42,57^{\mathrm{B}, 5} \pm 7,22$ & $24,54^{\mathrm{C}, 6} \pm 5,56$ \\
\hline
\end{tabular}

The data are normalized against the control group (cells treated with unconditioned medium). Values represent means (standard deviations) and are expressed as relative percentages of the control group (set to $100 \%$ ). For each column, data with different letter superscripts denote significant difference $(p<0.05)$. For each row, data with different numerical superscripts denote significant difference $(p<0.05)$.

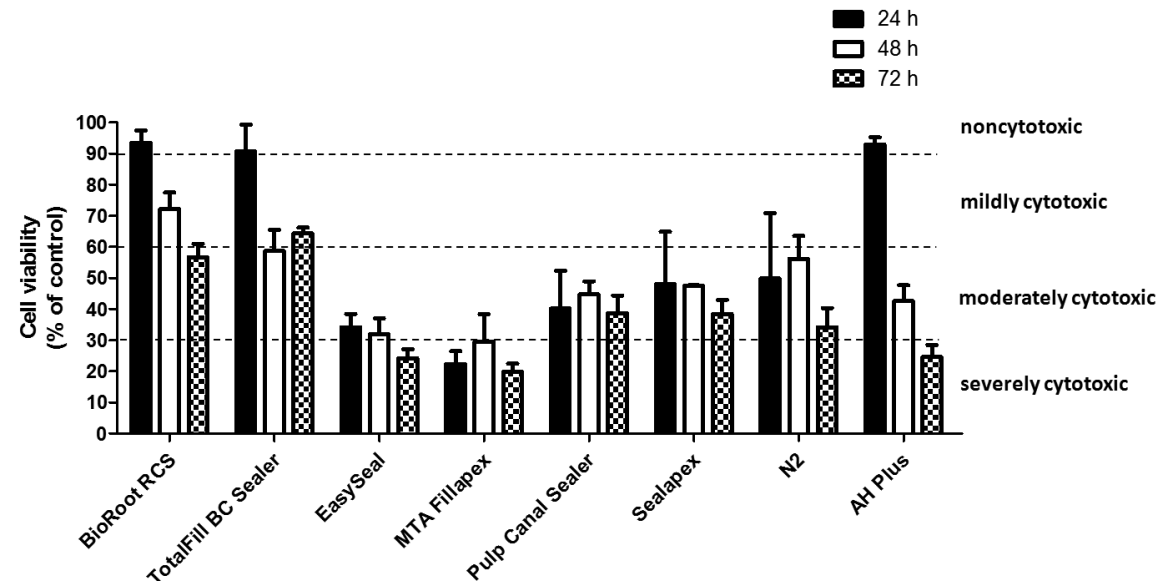

Fig. 1: Cell viability in the presence of the elute extracts from eight root canal sealers. Confluent human gingival fibroblast were treated for 24 hours with extracted medium made eluting the sealers for 24 hours, 48 hours or 72 hours. The cell viability was measured by the MTT assay. Values are expressed as percentages relative to the control group and classified as severe $(<30 \%)$, moderate $(<60 \%)$, mild (60-90\%) or non-cytotoxic $(>90 \%)$. Bars and error bars represent the means and \pm SD from three independent determinations performed in triplicate. 
EasySeal and MTA Fillapex remained severely or borderline mildly cytotoxic for all the extraction times. After $72 \mathrm{~h}$ of elution, both sealers exhibited a toxicity level that was significantly more severe $(p<0.05)$ than the other tested sealers.

When cytotoxicity was moderate or severe, cells died by apoptosis (data not shown). Rounding and detachment of the cells from the plastic wells are the typical apoptotic events observed by optical light microscope.

\section{Discussion}

Root canal sealers should be biocompatible because they might extrude thought the apical constriction and contact intimately the soft periodontal tissue. When out of the root canal, a sealer could induce cytotoxic damage to tissue and have different level of cytotoxicity over a period of 24,48 or 72 hours $(1,2)$. Is important to evaluate sealers over different periods after setting because they probably change their cytotoxicity due to diffusion of toxic components resulting from the degradation of the components of the sealers. Freshly mixed materials are analysed because previous reports have shown that the cytotoxicity of sealers is higher immediately after mixing $(5,6)$. Further more it is important to consider the cell type that could be choose for the in vitro biocompatibility study. In this study immortalized human gingival fibroblast are chosen for the close relation between them and endodontic sealers and cements $(7,8)$. The human gingival fibroblasts can be cultured in a low number of passages, resulting in minimal cell changes due to cell culture manipulation (9).

This study is created to determine the cytotoxic properties of eight endodontic sealers on fibroblasts: to evaluate cell viability in the presence of the extract from eight root canal sealers, a MTT assay was performed.

In agreement with our results, BioRoot RCS extracted for $24 \mathrm{~h}$ shows no cytotoxic effect, while it is mild by using 48 and $72 \mathrm{~h}$ extracts (10). However, differences in cytotoxicity for all the times are not statistically significant $(p>0.05)$ compared to the control (11). Similar results are obtained with TotalFill BC Sealer that has no cytotoxic effect at $24 \mathrm{~h}$ after setting (12), while it is mild at 48 and 72h. Despite this, as previously said for BioRoot RCS, differences in cytotoxicity for all the times are not statistically significant compared to the control. No cytotoxic effect is measured by using AH Plus medium eluted for $24 \mathrm{~h}$, while it is moderate after $48 \mathrm{~h}$ and severe after $72 \mathrm{~h}$. The current results are partially in accordance with previous studies, which demonstrated the cytotoxic effects of AH Plus $(13,14)$.

EasySeal and MTA Fillapex remain severely or borderline mildly cytotoxic for all the extraction times. After $72 \mathrm{~h}$ of elution, both sealers exhibit a toxicity level that is significantly more severe $(p<0.05)$ than the other tested sealers. MTA Fillapex was developed in an attempt to combine the physicochemical properties of an endodontic sealer with the excellent biological properties of MTA. According to the present results, MTA Fillapex shows a severe cytotoxicity when cells are exposed to the fresh elutes of the sealer $(13,15,16)$.

MTA Fillapex remains severely and mildly cytotoxic over the entire experimental period. These results suggest correlations between the components, such as salicylate resin and diluting resin with the cytotoxic effects (2).

Similar results are obtained with EasySeal, a resin-based sealer that shows borderline cytotoxicity during all three different extraction times.

Pulp Canal Sealer, Sealapex and N2 show moderately cytotoxic activity for all the extraction times. In agreement with our results, zinc oxide-eugenol-based sealers have been shown to be cytotoxic, which has been attributed to the eugenol present in different formulations.

Biocompatibility of an endodontic sealer is one of the basic conditions for a successful endodontic treatment and healing of the periodontium. So, considerations for choosing an adequate root canal sealer include its physical properties and biocompatibility, but, despite the irritability that endodontic sealers may cause to periapical tissues, endodontists should evaluate the advantages and disadvantages of sealer extrusion (2).

In the present study only BioRoot RCS, TotalFill BC Sealer and AH Plus showed no cytotoxic effects at least in the first $24 \mathrm{~h}$. The other sealers tested revealed moderately or severely cytotoxic activity during all the extraction times.

\section{References}

1. Ricucci D, Langeland K. Apical limit of root canal instrumentation and obturation, part 2. A histological study. Int Endod J. 1998;31:394409 .

2. Silva EJ, Santos CC, Zaia AA. Long-term cytotoxic effects of contemporary root canal sealers. J Appl Oral Sci. 2013;21:43-7.

3. Torabinejad M, Hong CU, McDonald F, Pitt Ford TR. Physical and chemical properties of a new root-end filling material. J Endod 1995;21:349-53.

4. International Organization for Standardization. ISO 10993-5: Biological evaluation of medical devices, part 5: tests for cytotoxicity: in vitro models. 1st edition. Geneva: ISO; 1997.

5. Eldiniz AU, Mustafa K, Ørstavik D, Dahl JE. Cytotoxicity of resin, calcium hydroxide and silicone-based root canal sealers on fibroblasts derived from human gingiva and L929 cells lines. Int Endod J. 2007;40:329-37.

6. Correa GT, Veranio GA, Silva LE, Hirata Junior R, Coil JM, et al. Cytotoxicity evaluation of two root canal sealers and a commercial calcium hydroxide paste on THP1 cell line by Trypan Blue assay. J Appl Oral Sci. 2009; 17:457-61.

7. Economides N, Pantelidou O, Kokkas A, Tziafas D. Short-term periradicular tissue response to mineral trioxide aggregate (MTA) as root-end filling material. Int Endod J. 2003;36:44-8.

8. Yoshino P, Nishiyama CK, Modena KC, Santo CF, Sipert CR. In Vitro Cytotoxicity of White MTA, MTA Fillapex and Portland Cement on Human Periodontal Ligament Fibroblasts. Brazilian Dental Journal. 2013; 24:111-6.

9. Karimjee CK, Koka S, Rallis DM, Gound TG. Cellular toxicity of mineral trioxide aggregate mixed with an alternative delivery vehicle. Oral Surg Oral Med Oral Pathol Oral Radiol Endod. 2006;102:E115-E20. 
10. Collado-González M, García-Bernal D, O-ate-Sánchez RE, Ortolani-Seltenerich PS, Lozano A, Forner L, Llena C, Rodríguez-Lozano FJ. Biocompatibility of three new calcium silicate-based endodontic sealers on human periodontal ligament stem cells. Int Endod J. 2016 Sep 26 [Epub ahead of print].

11. Camps J, Jeanneau C, El Avachi I, Laurent P, About I. Bioactivity of a Calcium Silicate-based Endodontic Cement (BioRoot RCS): Interactions with Human Periodontal Ligament Cells In Vitro. J Endod. 2015;41:1469-73.

12. Zhou HM, Du TF, Shen Y, Wang ZJ, Zheng YF, Haapasalo M. In vitro cytotoxicity of calcium silicate-containing endodontic sealers. J Endod. 2015;41:56-61.

13. Silva EJ, Rosa TP, Herrera DR, Jacinto RC, Gomes BP, Zaia AA. Evaluation of cytotoxicity and physicochemical properties of calcium silicate-based endodontic sealer MTA Fillapex. J Endod. 2013;39:274-7.

14. Candeiro GT, Moura-Netto C, D'Almeida-Couto RS, AzambujaJúnior N, Marques MM, Cai S, et al. Cytotoxicity, genotoxicity and antibacterial effectiveness of a bioceramic endodontic sealer. Int Endod J. 2015 Aug 17 [Epub ahead of print].

15. Silva EJ, Zaia AA, Peters OA. Cytocompatibility of calcium silicate-based sealers in a three-dimensional cell culture model. Clin Oral Invest. $2016 \mathrm{Jul} 26$ [Epub ahead of print].

16. Rodríguez-Lozano FJ, García-Bernal D, Oñate-Sánchez R, Ortolani-Seltenerich PS, Forner L, Moraleda JM. Evaluation of cytocompatibility of calcium silicate-based endodontic sealers and their effects on the biological responses of mesenchymal dental stem cells. Int Endod J. 2017;50:67-76

\section{Conflict of Interest}

The authors have declared that no conflict of interest exist. 